\title{
Satellite observed widespread decline in Mongolian grasslands largely due to overgrazing
}

\author{
THOMAS HILKER*, ENKHJARGAL NATSAGDORJ†, RICHARD H. WARING*, \\ ALEXEI LYAPUSTIN $\$$ and YUJIE WANG $\$ \S$ \\ *College of Forestry, Oregon State University, Corvallis, OR 97331, USA, †National University of Mongolia, Ulaanbatar, \\ Mongolia, $\$ N A S A$ Goddard Space Flight Center, 8000 Greenbelt Road, Greenbelt, MD 20771, USA, §Joint Center for Earth \\ System Technology JCET, University of Maryland, Baltimore County, 1000 Hilltop Circle, Baltimore, MD 21250, USA
}

\begin{abstract}
The Mongolian Steppe is one of the largest remaining grassland ecosystems. Recent studies have reported widespread decline of vegetation across the steppe and about $70 \%$ of this ecosystem is now considered degraded. Among the scientific community there has been an active debate about whether the observed degradation is related to climate, or over-grazing, or both. Here, we employ a new atmospheric correction and cloud screening algorithm (MAIAC) to investigate trends in satellite observed vegetation phenology. We relate these trends to changes in climate and domestic animal populations. A series of harmonic functions is fitted to Moderate Resolution Imaging Spectroradiometer (MODIS) observed phenological curves to quantify seasonal and inter-annual changes in vegetation. Our results show a widespread decline (of about $12 \%$ on average) in MODIS observed normalized difference vegetation index (NDVI) across the country but particularly in the transition zone between grassland and the Gobi desert, where recent decline was as much as $40 \%$ below the 2002 mean NDVI. While we found considerable regional differences in the causes of landscape degradation, about $80 \%$ of the decline in NDVI could be attributed to increase in livestock. Changes in precipitation were able to explain about 30\% of degradation across the country as a whole but up to $50 \%$ in areas with denser vegetation cover $(P<0.05)$. Temperature changes, while significant, played only a minor role $\left(r^{2}=0.10, P<0.05\right)$. Our results suggest that the cumulative effect of overgrazing is a primary contributor to the degradation of the Mongolian steppe and is at least partially responsible for desertification reported in previous studies.
\end{abstract}

Keywords: grassland decline, MAIAC, MODIS, Mongolia, NDVI, over-grazing, time-series

Received 7 June 2013; revised version received 8 August 2013 and accepted 14 August 2013

\section{Introduction}

The Mongolian Steppe is one of the largest remaining grassland ecosystems in the world (Kawamura et al., 2007) spanning an area of about 1.17 million square kilometers (Fernandez-Gimenez \& Allen-Diaz, 1999) and encompassing roughly $2.6 \%$ of the global grassland vegetation ( $\mathrm{Li}$ et al., 2005). While Mongolia's vegetation has been described in general (Kalinina, 1974; Lavrenko \& Karamysheva, 1993) and some plant communities have been studied (Pacyna, 1986; Wallis de Vries et al., 1996), relatively little is known about the ecosystems vulnerability to human activity and climate change (Sugita et al., 2007). Recent decades have seen significant decline in grasslands across the country (Ykhanbai et al., 2004) and over $70 \%$ of the steppe is now considered degraded (UNEP, 2002). At the same time, there has been a dramatic increase in livestock numbers in Mongolia (Gong Li et al., 2000); domestic animal populations

Correspondence: Thomas Hilker, tel. 541737 2608,

fax 541737 4316, e-mail: thomas.hilker@oregonstate.edu have almost doubled from 26 million sheep, goats, horses, cattle, camels and yaks in 1990 to about 45 million animals in 2012 (National Statistical Office of Mongolia - NSO, 2012). The increase in animal population was mainly caused by socio-economic changes (particularly the breakdown of the Soviet Union), as the country's centralized economy turned into a market economy (Gong Li et al., 2000). The resulting unemployment drove parts of the population back into the country side to subsist by increasing the domestic animal herds (Reading et al., 2006).

Within the scientific community, there has been much debate (Vetter, 2005) about whether the observed decline in steppe vegetation is related to climate, or over-grazing, or both (Fernandez-Gimenez \& AllenDiaz, 1999; Opp \& Hilbig, 2003). Overgrazing has been reported as a major factor of desertification in the neighboring province of Inner Mongolia (China) (Gong Li et al., 2000), where decline in available grassland combined with increase in herd sizes has increased the pressure on the remaining pastures, thus accelerating desertification (Yiruhan et al., 2001). On the other hand, 
extreme winter conditions (so called dzud), drought and fire, frequently diminish herd sizes, as in 2009/ 2010 when more than 8 million animals were lost (NSO, 2012).

The observed decline in grassland vegetation could have significant social and ecological impacts regionally and even globally. For instance, related hydrological changes of the land surface have been shown to affect regional climate (Gong Li et al., 2000), soil properties (Yong-Zhong et al., 2005) and water table (Jia et al., 2006). The Mongolian steppe ecosystems play an important role in mitigating regional and even global climate variation through their interaction with the atmosphere (Yatagai \& Yasunari, 1995). In addition, grassland ecosystems can act as either a significant sink or source for atmospheric $\mathrm{CO}_{2}$, thereby potentially contributing to or slowing global climate change (Frank, 2002).

One way to evaluate grassland dynamics at broader scales is through time series of remote sensing data. Historically, $8 \mathrm{~km}$ Normalized Difference Vegetation Index (NDVI) data from the National Ocean and Atmospheric Administration advanced very high resolution radiometer (AVHRR) have been used to investigate large-scale spatial and temporal patterns of vegetation response to climate (Myneni et al., 1997a, b) and photosynthetic capacity (Tucker et al., 2001) since the early 1980 's. AVHRR's ability to detect subtle changes in vegetation dynamics was limited due to instrument noise, atmospheric, snow and cloud effects, which made it difficult to obtain significant trends in vegetation over time (Fensholt \& Proud, 2012). Arguably, the advent of Moderate Resolution Imaging Spectroradiometer (MODIS) providing near daily coverage at $250 \mathrm{~m}-1 \mathrm{~km}$ resolution has revolutionized earth system science from space, however, some challenges remain with respect to removal of atmospheric and cloud effects, at least for some regions of the world, including tropical (Hilker et al., 2012) and sparsely vegetated areas (Steinberg et al., 2006). Recently, a new multi-angle implementation of atmospheric correction algorithm (MAIAC) (Lyapustin et al., 2011a,b) has shown promise to overcome some of these challenges using an advanced radiative transfer model for aerosol retrieval, atmospheric correction and cloud screening (Lyapustin \& Knyazikhin, 2002; Lyapustin et al., 2012). For instance, in previous research across 2 million square kilometers of the Amazon basin, Hilker et al. (2012), demonstrated that MAIAC can reduce uncertainties in surface reflectance up to 10-fold compared to the standard MODIS surface reflectance.

In this study, we use MAIAC to investigate changes in vegetation dynamics between 2002 and 2012 based on daily MODIS observations. Our objectives are first, to derive trends in vegetation greenness between 2002 and 2012 based on the NDVI (Tucker, 1979) and second, to compare these trends to changes in climate variables and livestock numbers to investigate potential causes for shifts in vegetation density.

\section{Materials and methods}

\section{Study area}

Our study area encompasses two MODIS tiles (h25v04 and h24v04), an area of 2 million square kilometers, spanning from roughly $40^{\circ} \mathrm{N}$ to $50^{\circ} \mathrm{N}$ in latitude and from $90^{\circ} \mathrm{E}$ to $120^{\circ} \mathrm{E}$ in longitude. Mongolia's climate is semi-arid and markedly continental with generally extremely cold, dry winters and warm, wet summers. Mean annual temperatures range from $-1.7{ }^{\circ} \mathrm{C}$ in the mountain-steppe to $4.8^{\circ} \mathrm{C}$ in the desert-steppe, and average annual precipitation ranges between $90 \mathrm{~mm}$ and $230 \mathrm{~mm}$ (Fernandez-Gimenez \& AllenDiaz, 1999), most of which falls from June through September (Jia et al., 2006). High mountain ranges isolate the country from the influence of the Ocean and the Siberian anticyclone determines winter climate with its low temperatures and precipitation rates. Vegetation zones depend on altitude, rainfall and soil type and span alpine tundra $(3.0 \%$ of total area), mountain taiga $(4.1 \%)$, mountain steppe $(25.1 \%)$, steppe $(26.1 \%)$, desert steppe $(27.2 \%)$ and desert (14.5\%) (Hilbig, 1995). Roughly, 124.3 million ha or $79 \%$ of land area are covered by grassland and about $10 \%$ are covered by forest or shrub land.

To characterize changes in climate over the last 30 years, we obtained monthly mean values of precipitation and temperature from the 64 available weather stations across the study area between 1980 and 2012 (National Agency for Meteorology, Hydrology \& Environment Monitoring, http://env. env.pmis.gov.mn/). The stations are well distributed across the country, spanning a range of different climate zones and vegetation types (Fig. 1).

\section{Animal populations}

Official estimates of animal populations were provided on a per-province basis by the National Statistical office (NSO) of Mongolia. NSO conducts annual surveys of total numbers of horses, cattle, sheep, goats and camels using data provided by ministries, other state organizations and governors of the respective provinces. These livestock estimates are also used as official numbers for industry, science and technology in the country.

\section{MAIAC data}

Daily MODIS data from the Aqua platform were collected between 2002/07/04 and 2012/12/31 and processed using the calibrated and geometrically corrected (Level 1B) data. We selected MODIS data from the Aqua spacecraft to minimize uncertainties in vegetation trends from the MODIS Terra calibration degradation (Wang et al., 2012). Level 1B 


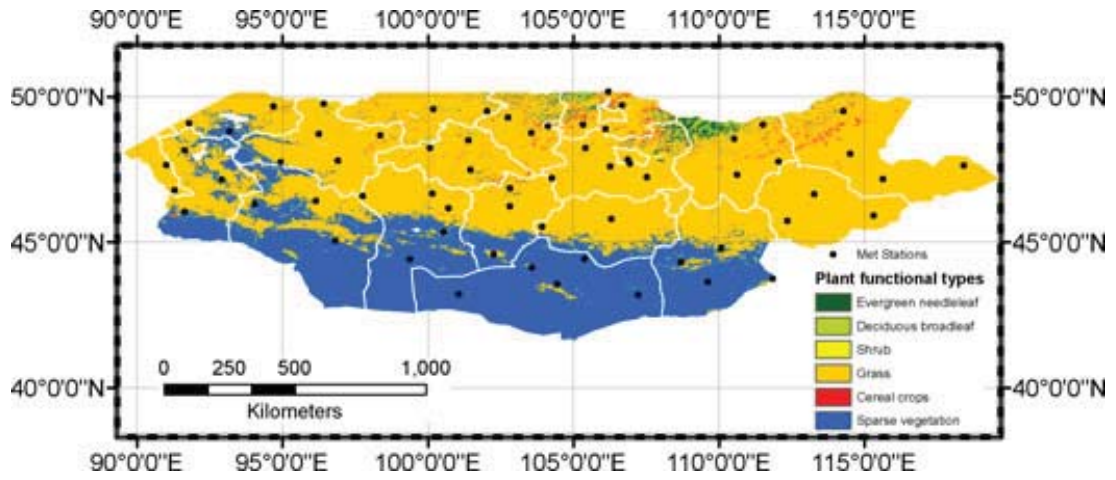

Fig. 1 Plant functional types derived from the MODIS Land cover product (MCD12Q1). The map presents data from 2002. Over 85\% of the study area was covered by grassland or sparse vegetation. The black dots symbolize the locations of meteorological stations used in this study.

data were processed using the MAIAC algorithm for cloud screening and atmospheric correction (Lyapustin \& Martonchik, 2011; Lyapustin et al., 2011a,b, 2012). MAIAC grids MODIS L1B data (MYD021KM) into $1 \mathrm{~km}$ pixels, and accumulates measurements of the same surface area from different orbits (view geometries) for up to 16 days of observations for equatorial and up to 4 days for polar regions using a moving window approach (Lyapustin et al., 2012). The MAIAC cloud mask algorithm composes a dynamically updated reference clear-sky image of the surface from spatial and time series analyses (Lyapustin et al., 2008). This allows cloud masking to be based on knowledge of reference clear-sky reflectance in addition to spectral and thermal thresholds, which can improve cloud detection considerably (Hilker et al., 2012). Along with better cloud recognition, the MAIAC technique improves aerosol retrieval (Lyapustin et al., 2012) and hence the atmospheric correction (Lyapustin et al., 2012) by applying advanced radiative transfer theory (Lyapustin \& Knyazikhin, 2001) that does not assume a Lambertian reflectance of the surface. The accumulated multi-angle dataset from multiple overpasses is used to derive parameters of the Ross Thick - Li Sparse (RTLS) BRDF model (Roujean et al., 1992) for every $1 \mathrm{~km}$ grid cell as well as the bidirectional reflectance factor (BRF, often called surface reflectance) for the last observation.

Multi-angle implementation of atmospheric correction algorithm surface products include parameters of BRDF model, $\mathrm{BRF}$ and albedo at $1 \mathrm{~km}$ resolution as well as spectral BRF at $500 \mathrm{~m}$ resolution. The BRF, or surface reflectance, has a significant variability with the view geometry. To mitigate this source of variability for trend analysis, we normalized BRFs for the fixed view geometry of sun zenith angle $\theta_{s}=45^{\circ}$ and nadir view $\left(\theta_{v}=0^{\circ}\right)$ using the known BRDF model:

$$
B R F_{n}=\frac{B R F \times R T L S\left(\theta_{s}, \theta_{v}, \Delta \phi\right)}{R T L S\left(\theta_{s}=45^{\circ}, \theta_{v}=0^{\circ}, \Delta \phi=0^{\circ}\right)}
$$

where $\Delta \phi$ is relative azimuth. Such normalization (e.g., Lyapustin et al., 2012) was shown to reduce geometric variability by a factor of 3-6 thereby helping to isolate seasonal changes and multi-year cycles and trends.

\section{Land cover types}

Different vegetation types have different ecological capacities to accommodate stresses induced by biotic or abiotic factors. Therefore, it makes sense to investigate changes in vegetation cover and their causes separately for different land cover types. In this study, we used the MODIS land cover product (MCD12Q1, type 5) (Friedl et al., 2010) to stratify time series of MAIAC observations into different plant functional types (Bonan et al., 2002). The MODIS land cover algorithm is based on an ensemble of supervised classification techniques and decision tree analysis to yield global land cover types (Friedl et al., 2010). Across Mongolia, the product differentiates between six different plant functional types (Fig. 1) however; the vast majority of the area is dominated by grassland and other sparse vegetation. To prevent changes in plant functional type from affecting vegetation trends (for instance if a pixel moves from one land cover class into another during the 10 year study period), we selected pixels only from areas where the plant functional types remained identical between 2002 and 2012 for analysis.

\section{Time series fitting}

Time series of satellite data can be used to derive trends in vegetation based on the assumption that changes in the measured reflectance are driven by phenological changes on the ground (Jönsson \& Eklundh, 2004). Principally, change detection can be done either using simple threshold techniques (Sellers et al., 1994) or function fitting (Jönsson \& Eklundh, 2004). While thresholds are easier to implement and resulting algorithms are fast, a functional description of changes in reflectance has the advantage in allowing seasonal progression to be separated from inter-annual progression ( $\mathrm{Zhu}$ et al., 2012). Fitting functions through time series data also reduces noise levels by smoothing the signal obtained from temporally discrete observations (Jönsson \& Eklundh, 2004). Different algorithms are available and have been applied (Jönsson \& Eklundh, 2004; Bradley et al., 2007); here we used a simple series of harmonic functions (Zhu et al., 2012) based on Fourier series (Davis \& Sampson, 2002). This method developed 
by Zhu et al. (2012) has been adapted in this study to be used for dense time series and across multiple years. One advantage of Zhu's harmonic model is that it requires only a relatively small number of clear observations, making predictions less sensitive to missing data. At the same time, the model is flexible enough to account for intra and inter-annual changes in reflectance (Zhu et al., 2012). These properties are particularly advantageous during the winter months in Mongolia where the number of snow free MODIS observations is limited and the ground may not be visible for several weeks or even months. Our inter-annual change model $(i=2,3,4 \ldots N)$ is comprised of sines and cosines to represent differences from one year to the next (Zhu et al., 2012):

$$
\begin{gathered}
f(x)=a_{0}+\sum_{i=1}^{N}\left(a_{i} \cos \left(\frac{2 \pi}{i T} x\right)+b_{i} \sin \left(\frac{2 \pi}{i T} x\right)\right)+ \\
a_{N+1} \cos \left(\frac{2 \pi}{0.5 T} x\right)+b_{N+1} \sin \left(\frac{2 \pi}{0.5 T} x\right)
\end{gathered}
$$

where $x$, day of year; $N$, number of years; $T$, number of days per year (365); $a 0$, coefficient to represent the overall surface reflectance; $a_{i}, b_{i}$, coefficients that capture changes of surface reflectance from one year to the next; $a_{N+1}, b_{N+1}$, coefficients that capture the bimodal variations of surface reflectance.

The algorithm allows quantification of changes from opportunistically acquired satellite observations and yields continuous predictions of reflectance or vegetation indices over time. Trends in vegetation from one year to the next can be quantified in terms of changes in annual mean, maximum and minimum reflectance and as integral of the modeled reflectance over the year. Our harmonic model was fitted to time series of NDVI separately for every pixel $(1200 \times 600$ locations $)$; trends were derived as inter-annual changes in the fitted curves. Specifically, we obtained the mean value for each 365 day interval from the fitted curve and derived inter-annual changes in NDVI as difference of these annual means.

Regional differences in factors driving changes in NDVI were investigated using a mixed-effects linear regression model (Lindstrom \& Bates, 1990; Pinheiro \& Bates, 1995) to assess local effects of changes in climate on NDVI. Mixed effects models account for fixed and random effects on the variability of a response variable by grouping predictor variables into fixed categories (Pinheiro \& Bates, 1995). In this study, climate anomalies were grouped using long term averages (2002-2010) of temperature, precipitation and vegetation density (NDVI), respectively, to investigate how climate change has affected arid vs. humid vegetation zones and sparsely vegetated vs. densely vegetated areas.

\section{Results}

Figure 2 shows total changes in livestock in Mongolia since 1980 (National Statistics Office of Mongolia). The figure presents estimated populations of camel, goat, sheep, cattle and horses across the country. While numbers in cattle and camels remained relatively constant throughout the observation period, a steep increase in sheep and, in particular, goat population has been

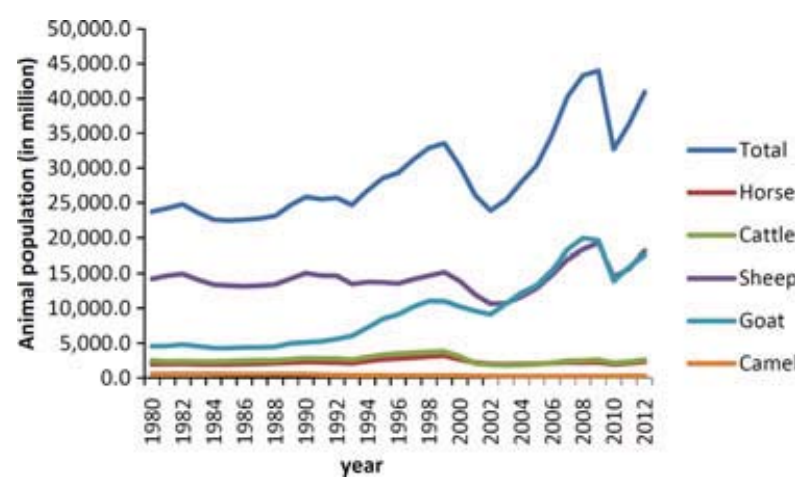

Fig. 2 Changes in livestock populations in Mongolia since 1980 (source: Statistical Office of Mongolia, NSO). The Figure shows a steady increase, particularly in sheep and goat since the early 1990s. The large increase since 2002 represents recovery from the massive die-back caused by the dzud conditions between 1999-2002.

recorded since the early 1990s. It is important to note the differences in species, as at least in situations where animal survival is in competition, goats are likely to cause significantly more damage than sheep, which in turn will cause more damage than cows (Wilson, 1986). The upward trend in number of animals was interrupted twice. The years 1999-2002 saw three dzud conditions in a row, accounting for the loss of about 11 million animals. In 2010, arctic oscillation events resulted in prolonged winter conditions, killing another 8 million heads of livestock. Despite these calamities, total animal populations almost doubled between 2002 and 2012. Animal populations grew mainly in the western provinces of the country, but increases in livestock occurred almost everywhere, with the exception of urban areas. Figure 3 shows the spatial distribution of cumulative changes in animal populations across the study area between 2002 (beginning of the MODIS record) and 2012. We show cumulative changes rather than simple differences because an increase in number of livestock early during the observation period exert pressure on the ecosystem longer than if it occurred during the last year of our study period. Cumulative herd sizes in the western part of the country reached up to 5.5 million, while the south eastern region saw moderate cumulative increases of up to 0.4 million.

During the same period, annual mean temperature in the country increased by about $1.5^{\circ} \mathrm{C}$ (Fig. 4) from $-0.4{ }^{\circ} \mathrm{C}$ in the early 1980 s to $1.2^{\circ} \mathrm{C}$ in 2010 (Temperature data were averaged from annual means using all 64 available meteorological stations shown in Fig. 1). Meteorological data also showed a decrease in precipitation of about $5 \%$ from, on average, $204 \mathrm{~mm} \mathrm{yr}^{-1}$ in the 1980 s to about $195 \mathrm{~mm} \mathrm{yr}^{-1}$ in the early and mid 2000s. Most of the warming occurred in the northern 


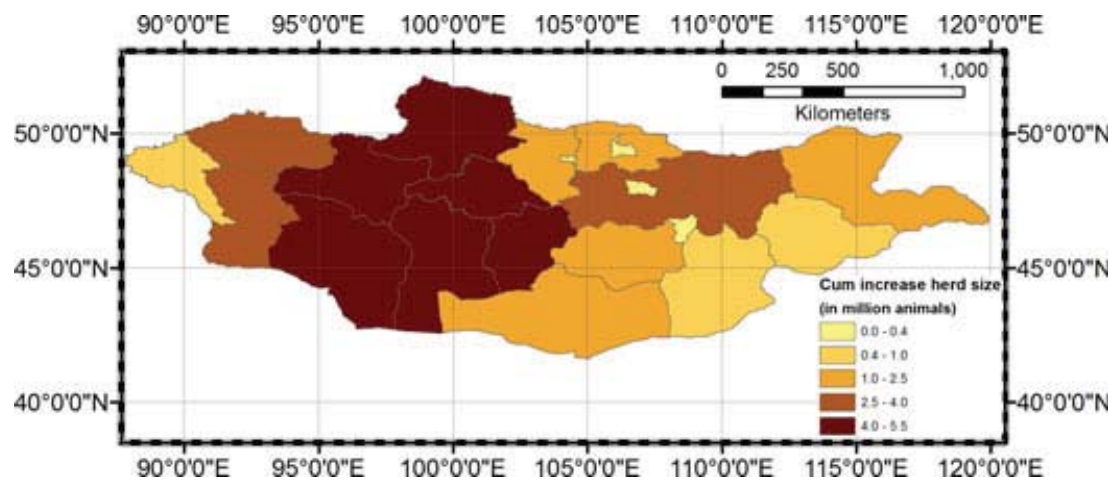

Fig. 3 Cumulative changes in herd sizes (in million animals) since 2002.

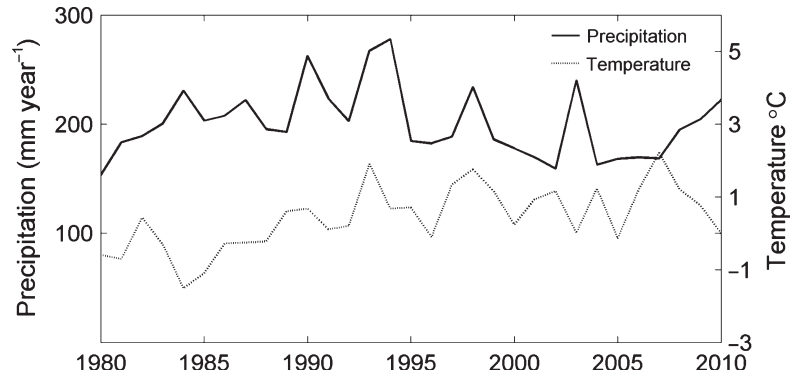

Fig. 4 Trends in average temperature and total annual precipitation across Mongolia between 1980-2010 (mean of all available weather stations).

and central provinces of the country (Fig. 5), with mean annual increases in temperature of up to $0.1^{\circ} \mathrm{C}$. Central Mongolia also experienced the largest decrease in annual precipitation, on average $0.4 \mathrm{~mm} \mathrm{yr}^{-1}$ over the 30 year period.

Figure 6 illustrates an example of a harmonic model used to fit NDVI series. This example originates from the northern part of the study area. Seasonal changes were large for this particular example, reflecting
Mongolia's continental climate. NDVI ranged from about 0.7 at the height of the growing season to 0.2 and the end of the growing season. The Figure also shows gaps in the analysis in the winter months, due to snow cover.

The quality of the MAIAC time series of observation is discussed in detail in Appendix S1. The harmonic model chosen in this study fitted the time series in this example well, although it somewhat underestimated the peak of the growing season. Figure 7 shows the standard error (SE) of the harmonic models fitted at each pixel location across the study area. The harmonic functions fitted the MODIS observations well. The SE was highest in the northern part for the study area (0.04-0.06) and lowest in the southern part of the country with sparse vegetation cover (0.01). Figure 8 shows changes in yearly mean NDVI (as linear trend between 2002 and 2012), derived using the annual mean of the harmonic model. Figure 8(a) presents annual mean NDVI as observed 2002. Mean NDVI was highest in the northern part of the study area reaching up to 0.5, whereas the southern region bordering the Gobi desert showed much lower values (0.1-0.2). Figure 8(b) presents changes in NDVI (delta NDVI) observed

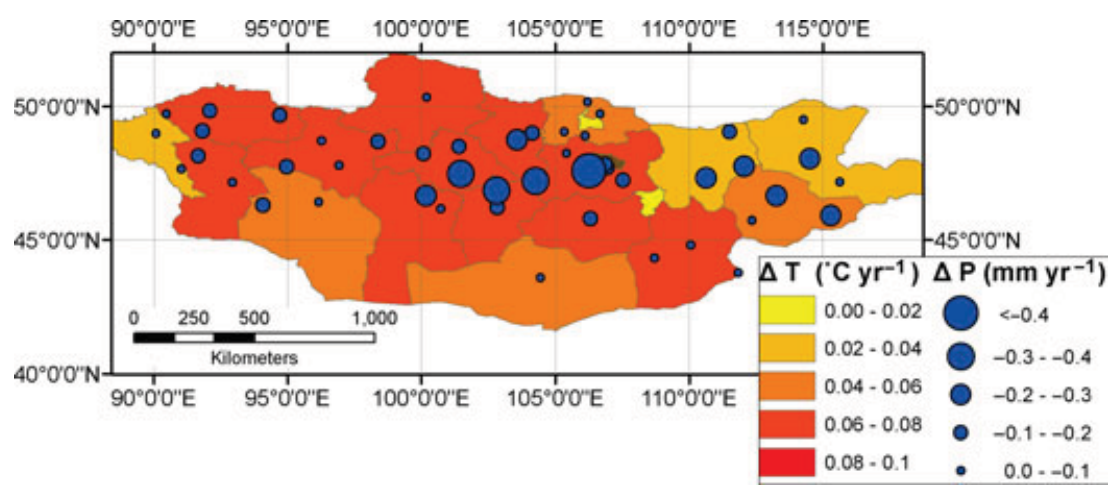

Fig. 5 Trends in temperature and precipitation between 1980 and 2010 by province. Changes were estimated as slope of linear trends for each weather station. 


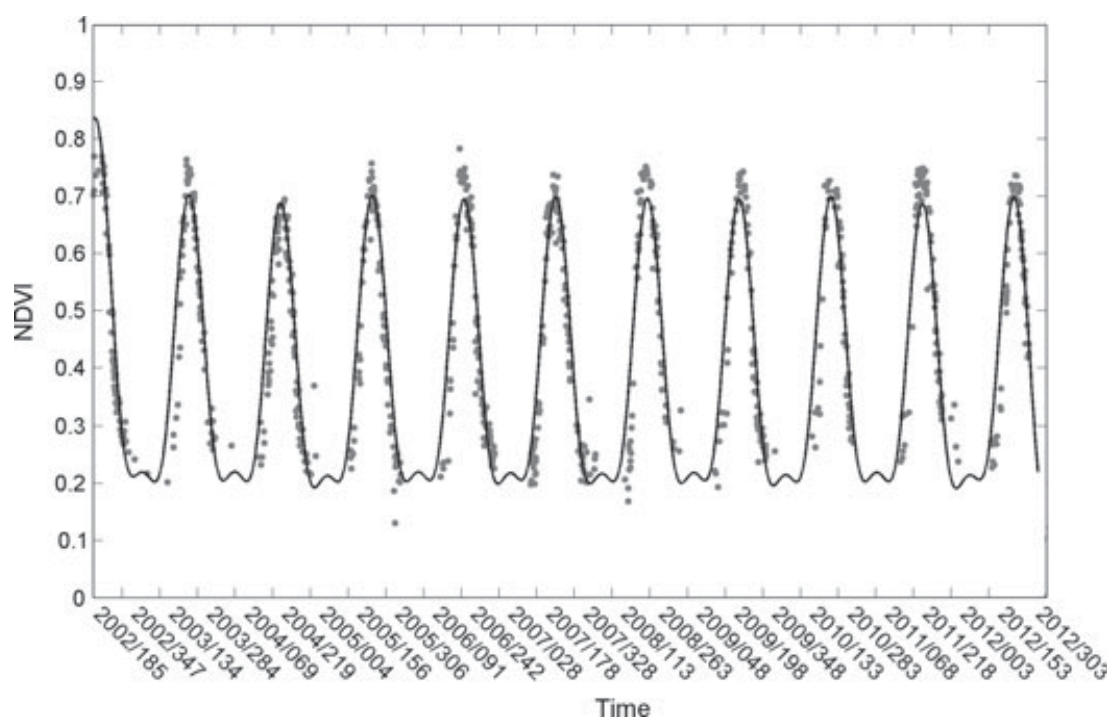

Fig. 6 Example of a harmonic fit using combined MODIS Aqua NDVI data acquired between 2000 and 2012. The gray dots represent NDVI MODIS MAIAC observations of NDVI, the black line is the fitted model between 2002 and 2012.

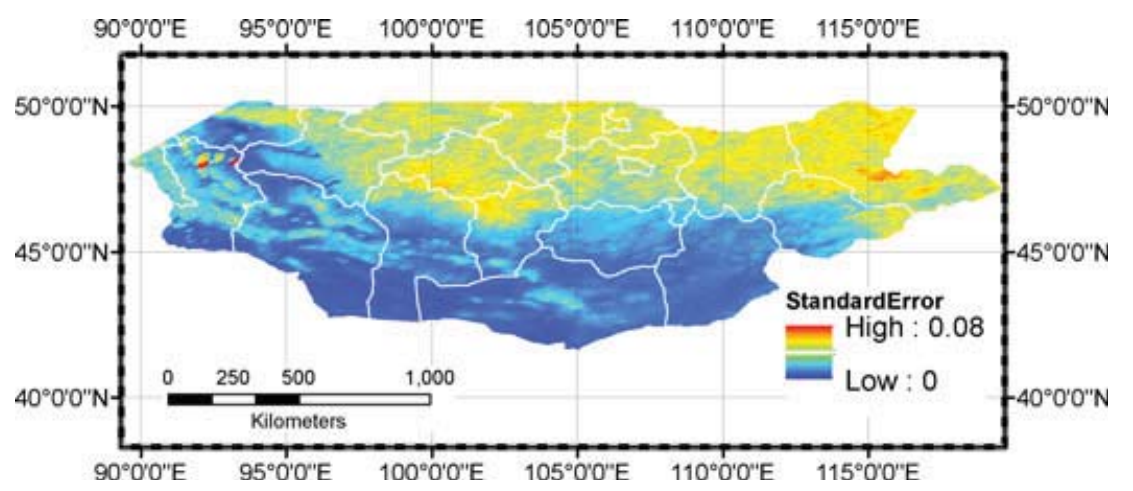

Fig. 7 Standard error (SE) of the harmonic model for BRF normalized NDVI data. The SE was around 5\% in the northern part and $1-2 \%$ in the southern part of the study area.
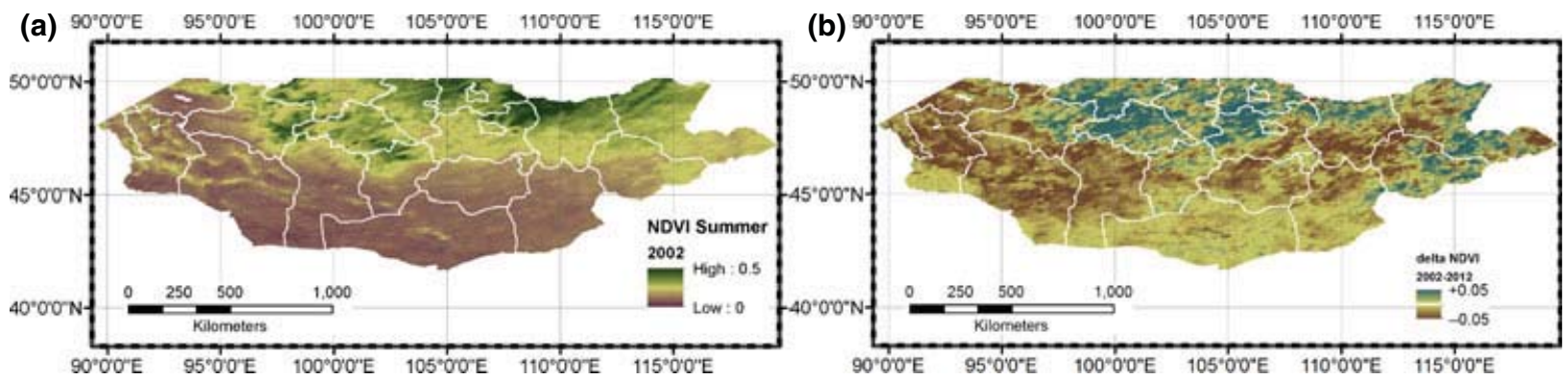

Fig. 8 (a) Mean NDVI over the 2002 growing season (May-September), (b) Changes in mean NDVI between 2002 and 2012, derived using the harmonic model.

between 2002 and 2012. While NDVI was relatively stable or increased in some areas in the north of the country, a decrease of up to 0.05 in yearly mean NDVI occurred over much of the southern provinces, especially in the most southern part of the country. The decline was especially pronounced across the southern 
edge of the grassland (compare Fig. 1) and along the transition into barren/sparse vegetation functional type. This region experienced 25-50\% decrease in NDVI compared to the 2002 values (Fig. 8a). Across the whole study area, NDVI decreased by 0.025 which corresponds to a decrease of about $12 \%$ of total mean NDVI observed in 2002.

Changes in NDVI were strongly related to cumulative increases in animal population. Figure 9 shows the relationship between mean annual changes in NDVI between 2002 and 2012 and cumulative change in herd size as reported for every province. Figure 9(a) shows the decline in grassland vegetation (plant functional type), Figure 9(b) shows the respective changes for the barren/sparse vegetation type. A strong linear relationship between cumulative increase in animal population and decrease in NDVI was found for both plant functional types, with $r^{2}$ values of 0.85 and 0.74 for grassland and sparse vegetation/barren types, respectively. Note that some of the very northern and western provinces were not fully contained in the two MODIS tiles used in this analysis. NDVI decreased by up to 0.07 in some provinces with cumulative increase in herd sizes were up to 5 million heads of livestock. For the sparse vegetation type, the corresponding decline in NDVI was about 0.02, presumably because those areas already had less vegetation cover at the start of the observation period.

Figure 10 shows the relationship between changes in NDVI and precipitation (a) and changes in NDVI and temperature. (b) Data are reported as deviation from the average annual mean between 2002 and 2012. NDVI
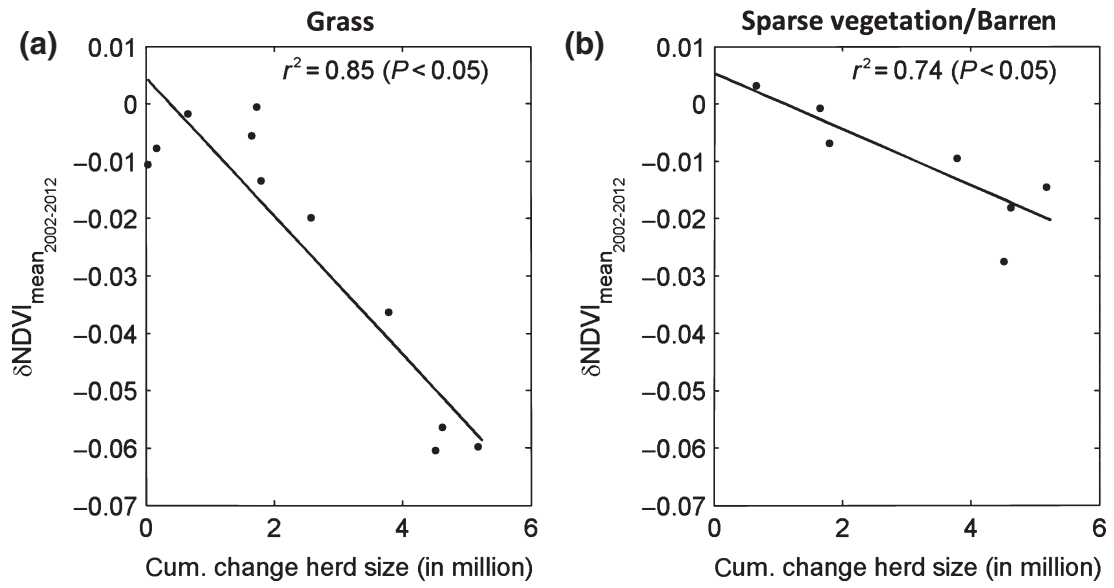

Fig. 9 Relationship between cumulative increase in animal population and decline in NDVI.
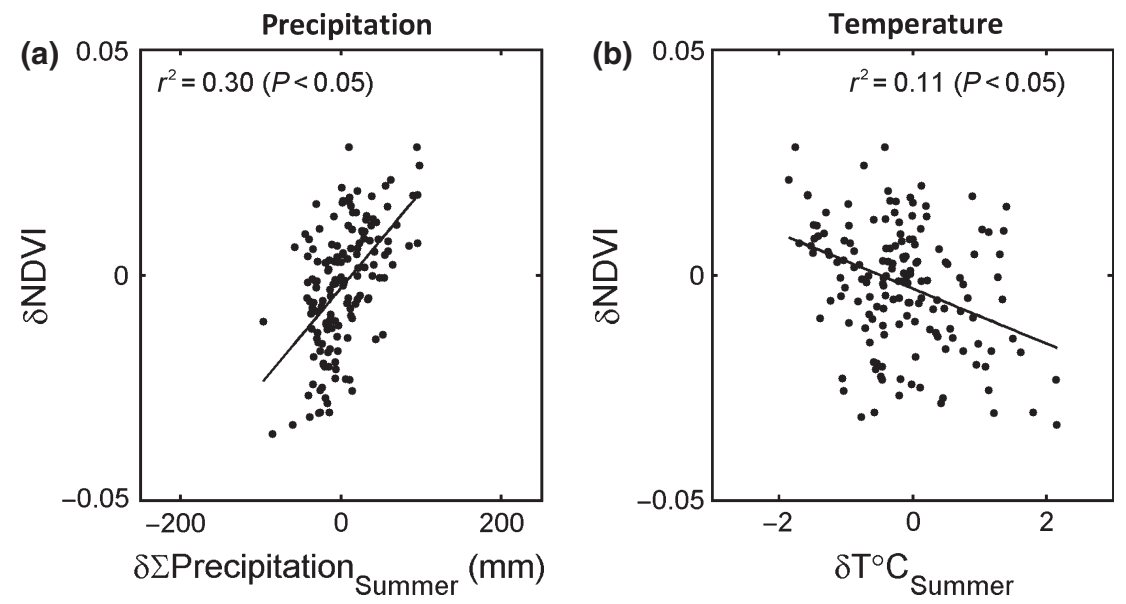

Fig. 10 (a) Relationship between changes in NDVI (as deviation from the long term average between 2002 and 2012) and changes in total summer precipitation (here defined as precipitation between May and September). Figure 10 (b) Relationship between changes in NDVI (as deviation from the long term average between 2002 and 2012) and deviation in mean annual temperature from the long term mean (as deviation from the long term average between 2002 and 2012). 
values varied by about 0.03 around the long term mean (2002-2012), whereas precipitation and temperature deviated by about $\pm 70 \mathrm{~mm}$ and $\pm 2{ }^{\circ} \mathrm{C}$, from their long term (2002-2012) mean values, respectively. As a whole, a moderate positive relationship was found between increase in summer precipitation (May through September) and NDVI $\left(r^{2}=0.30 ; P<0.05\right)$ and a weak negative relation was found between increase in temperature and NDVI $\left(r^{2}=0.11 ; P<0.05\right)$. The values shown here were averaged by provinces to make the results more comparable to those presented in Fig. 9.

While climatic changes explained about $30 \%$ of vegetation decline across the country as a whole, our mixed effects model showed considerable regional differences in the climatic effects on NDVI (Fig. 11). From the fixed effects that were investigated in this study (average vegetation density, average precipitation rate and average temperature), only vegetation density had a significant impact on the relationship between climate anomalies and NDVI anomalies. In densely vegetated areas (mean NDVI > 0.60), anomalies in precipitation explained about to $50 \%$ of the anomalies in NDVI $(P<0.05)$. In sparsely vegetated areas (NDVI $<0.2)$ less than $10 \%$ of changes in NDVI were explained by changes in precipitation (Fig. 11(a), $P<0.05$ ). Similarly, temperature anomalies explained about $20 \%$ of changes in NDVI $(P<0.05)$ in the densely vegetated north and north-east of the country, while the effect on most of the grassland area in the south and west was insignificant. We also related NDVI anomalies to changes in precipitation (Fig. 11a) and temperature (Fig. 11b), separately for each meteorological station. For most meteorological stations located in the south, only weak relationships were found between changes in NDVI and changes in precipitation and temperature, while climate anomalies generally explained more of the inter-annual variability in NDVI at meteorological stations located in denser vegetated areas (Fig. 11).

\section{Discussion}

We have observed and analyzed changes in grassland vegetation across Mongolia using MODIS satellite data between 2002 and 2012. A key finding of this study is that the degradiation in grasslands over the last 10 years across Mongolia (on average by about $12 \%$ of mean NDVI observed in 2002) is mainly related to an increase in domestic animal populations, and to a more limited extent, to changes in precipation patterns. While it is difficult from remote sensing data alone to assess to what extend this decrease in NDVI translates into decrease in plant biomass, it can be assumed that the decline should be in about the same range, at least in the southern regions, as the relationship between NDVI and vegetation leaf area is linear for leaf areas of less than about $4 \mathrm{~m}^{2} \mathrm{~m}^{-2}$ (Carlson \& Ripley, 1997; Myneni et al., 1997b; Turner et al., 1999). The observed degradiation in vegetation is well supported by previous studies, based mainly on data acquired from ground observations (Fernandez-Gimenez \& Allen-Diaz, 1999; Stumpp et al., 2005), but also AVHRR satellite observations (Sternberg et al., 2011; Liu et al., 2013). We found most degradiation in the central and southern part of the country, particularly in the transition zone between grassland and barren/sparse vegetation with up $40 \%$ decline compared to 2002. This finding suggests that grasslands are retreating rapidly in the transition zone, thus leading to expansion of deserted areas (Sternberg et al., 2011). Changes in summer precipitation seem to play some role in this decline (Fig. 10), especially in the central and eastern part of the country (Figs 5 and 11). While significant regional differences were found on the impact of changes in precipitation

(a)

(b)

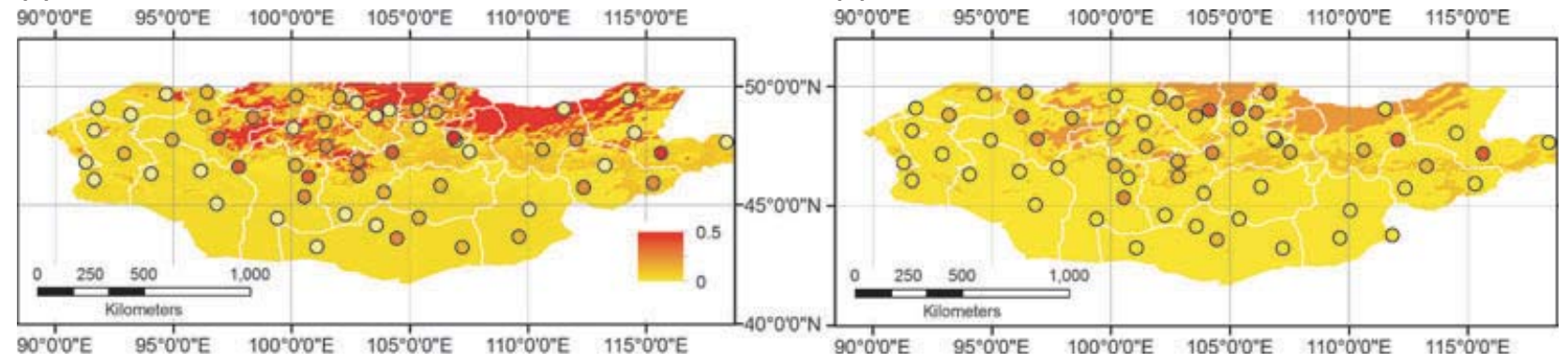

Fig. 11 Regional differences in the variance explained in NDVI across the country using mixed effects models. The map colors indicate the coefficient of determination $\left(r^{2}\right)$ for the relationship between precipitation anomalies and NDVI anomalies (Fig. 11a) and temperature anomalies and NDVI anomalies (Fig. 11b). In both cases long term mean NDVI was used as a grouping variable (steps of 0.2 from 0 to 1). The color of the dots represents the strength of the relationship $\left(r^{2}\right)$ between precipitation anomalies and NDVI anomalies (Fig. 11a) and temperature anomalies and NDVI anomalies (Fig. 11b) at individual meteorological stations. 
patterns on vegetation decline, our findings suggest that over-grazing is the single most important reason for desertification of the Mongolian Steppe. This conclusion is supported by similar studies from neighboring Inner Mongolia (China), that have identified overgrazing as a major cause of desertification (Gong $\mathrm{Li}$ et al., 2000). Zhao et al. (2005) showed that heavy grazing results in a considerable decrease in vegetation cover, root biomass, and an increase in animal hoof impacts. Batjargal (1997) identified livestock grazing as most prevalent human-related activity contributing to land degradation in the area. Liu et al. (2013) reported a steady decline in vegetation across Mongolia between 1998 and 2008. They attributed changes mostly to climatic shifts, based on radar derived vegetation optical depth. While their results seemingly contradict the findings of this work, the discrepancies may be explained by regional differences in the factors driving decline in vegetation and the complex interactions between them. For instance, Liu et al. (2013) considered only increases in goat populations, which were mostly limited to central Mongolia (Liu et al., 2013). In this region, our study has shown the strongest decline in precipitation (Fig. 5), which had a clear negative effect on vegetation growth (Fig. 11). We found similar results for the north-eastern part of Mongolia, changes in precipitation, however, could not explain the vegetation decline observed across large areas in the southern and western part of the country (Figs 8 and 11). Overgrazing and climate variabity therefore need to be understood as two extremes along a gradient, rather than contradicting theories (Illius \& O'connor, 1999). For instance, our results suggest that degradation in central Mongolia is largely caused by overgrazing, however, changes in summer preciptation have occurred (Fig. 5) and they had a clear impact on regeneration of grasslands (Fig. 11). Such changes may become more important once critical thresholds are reached and exceeded.

Our analysis benefited from using an improved surface reflectance product (MAIAC), thereby confirming the value of previous work (Hilker et al., 2012) by demonstrating that high quality reflectance data can be consistently derived from this product (Figs 6 and 7). While 11 years of time series from MODIS/MAIAC is relatively short, results presented in the appendix have shown that MAIAC processed MODIS data allow a more accurate assessment of land degradation compared to for instance AVHRR. In addition, results presented in Fig. 2 show that increase in livestock has not been linear over the last 30 years; in fact, the vast majority of it has occurred since the early 2000s. As a result, it can be assumed that the majority of livestock-related disturbance has happened since then.
The higher error in MAIAC derived NDVI in the northern part of the country could be due to snow cover, which led to extended periods during which no valid estimates of ground cover could be made), or the inability of multi-harmonic model to accurately fit the seasonality (e.g., underestimation of NDVI peaks in Fig. 6).

The selected time series model fitted the observations generally well, as shown in the example of Fig. 6 and by the standard error presented in Fig. 7. These results compare well also to previous studies based on Landsat observations (Zhu et al., 2012). While the approach applied in this study was successful, it may be limited in other areas, as it makes the assumption that vegetation has only a one season cycle, and it excluded places where a change in vegetation type may have occurred. While several other techniques are available (Jönsson \& Eklundh, 2004; Huang \& Wu, 2008) that do not apply such assumptions and exclusions, our technique is more likely to be insensitive to data gaps, for instance as a result of prolonged snow cover, than alternative procedures.

While we were able to associate recent decline in grassland with grazing, it is unknown to what extend changes in climate may have contributed to predisposing the steppe ecosystem to stress. Temperatures have increased considerably over the last 30 years across the country, but its effect on vegetation was limited, at least over the last 10 years. It is reasonable to assume that in semi-arid environments, water, rather than temperature limit growth (see Fig. 10a). An increase in temperature could therefore affect plant growth in a negative way, because it will enhance in latent heat flux, therefore increasing the amount of water evaporating from the surface.

We have shown a clear connection between increases in animal population and decline in vegetation density. This trend has continued despite two major die-offs of animal populations during harsh winter conditions. We recognize that our study was limited to studying very recent climate related impacts on grassland vegetation. Longer-term trends in climate were not evaluated and may play a significant role, particularly if extreme events are becoming more frequent.

\section{Acknowledgements}

We would like to thank Dr. Paul Doescher (Oregon State University) for providing funding for Ms. Natsagdorj to work on this project. RHW contributions to this paper are an extension of his research supported by NASA grant NNX11A029G. The work of Drs. Lyapustin and Wang was supported by the NASA Science of Terra and Aqua Program. Thanks to the National Statistical Office of Mongolia and the Institute of Metrological Hydrology for providing meteorological and animal population 
data used in this study. We would like to thank Drs. Woodcock and Zhu for helpful discusions regarding the harmonic functions used to fit the time series of satellite data in this study.

\section{References}

Batjargal Z (1997). In Proceedings of the International Workshop on Rangeland Desertification. RALA Report (Vol. 200).

Bonan GB, Levis S, Kergoat L, Oleson KW (2002) Landscapes as patches of plant functional types: an integrating concept for climate and ecosystem models. Global Biogeochemical Cycles, 16, 5-1-5-23.

Bradley BA, Jacob RW, Hermance JF, Mustard JF (2007) A curve fitting procedure to derive inter-annual phenologies from time series of noisy satellite NDVI data. Remote Sensing of Environment, 106, 137-145.

Carlson TN, Ripley DA (1997) On the relation between NDVI, fractional vegetation cover, and leaf area index. Remote Sensing of Environment, 62, 241-252.

Davis J, Sampson R (2002) Statistics and Data Analysis in Geology. (3rd edn). Wiley, New York.

Fensholt R, Proud SR (2012) Evaluation of Earth observation based global long term vegetation trends-Comparing GIMMS and MODIS global NDVI time series. Remote sensing of Environment, 119, 131-147.

Fernandez-Gimenez ME, Allen-Diaz B (1999) Testing a non-equilibrium model of rangeland vegetation dynamics in Mongolia. Journal of Applied Ecology, 36, 871885 .

Fontana FMA, Coops NC, Khlopenkov KV, Trishchenko AP, Riffler M, Wulder MA (2012) Generation of a novel $1 \mathrm{~km}$ NDVI data set over Canada, the northern United States, and Greenland based on historical AVHRR data. Remote Sensing of Environment, 121, 171-185.

Frank A (2002) Carbon dioxide fluxes over a grazed prairie and seeded pasture in the Northern Great Plains. Environmental Pollution, 116, 397-403.

Frey RA, Ackerman SA, Liu Y, Strabala KI, Zhang H, Key JR, Wang X (2008) Cloud detection with MODIS. Part I: improvements in the MODIS cloud mask for collection 5. Journal of Atmospheric and Oceanic Technology, 25, 1057-1072.

Friedl MA, Sulla-Menashe D, Tan B, Schneider A, Ramankutty N, Sibley A, Huang X (2010) MODIS Collection 5 global land cover: algorithm refinements and characterization of new datasets. Remote Sensing of Environment, 114, 168182.

Gong Li S, Harazono Y, Oikawa T, Zhao HL, Ying He Z, Chang XL (2000) Grassland desertification by grazing and the resulting micrometeorological changes in Inner Mongolia. Agricultural and Forest Meteorology, 102, 125-137.

Hilbig W (1995) The Vegetation of Mongolia. SPB Academic Publishing, Amsterdam.

Hilker T, Lyapustin AI, Tucker CJ, Sellers PJ, Hall FG, Wang Y (2012) Remote sensing of tropical ecosystems: atmospheric correction and cloud masking matter. Remote Sensing of Environment, 127, 370-384.

Huang NE, Wu Z (2008) A review on Hilbert-Huang transform: method and its applications to geophysical studies. Reviews of Geophysics, 46, RG2006.

Illius AW, O'connor TG (1999) On the relevance of nonequilibrium concepts to arid and semiarid grazing systems. Ecological Applications, 9, 798-813.

Jia B, Zhou G, Wang Y, Wang F, Wang X (2006) Effects of temperature and soil watercontent on soil respiration of grazed and ungrazed Leymus chinensis steppes, Inner Mongolia. Journal of Arid Environments, 67, 60-76.

Jönsson P, Eklundh L (2004) TIMESAT-a program for analyzing time-series of satellite sensor data. Computers \& Geosciences, 30, 833-845.

Kalinina A (1974) Main Types of Pastures of Mongolia, their Structure and Productivity. Biological Resources and Natural Conditions of the Mongolian People's Republic. II. Izdatalestvo Nauka, Leningrad, [in Russian].

Kawamura K, Akiyama T, Yokota H, et al. (2007) Monitoring of forage conditions with MODIS imagery in the Xilingol steppe, Inner Mongolia. International Journal of Remote Sensing, 26, 1423-1436.

Lavrenko EM, Karamysheva ZV (1993) Steppes of the Former Soviet Union and Mongolia. Elsevier, Amsterdam.

Li X, Strahler AH (1986) Geometric-optical bidirectional reflectance modeling of a conifer forest canopy. IEEE Transactions on Geoscience and Remote Sensing, 6, 906-919.

Li SG, Asanuma J, Eugster W, Kotani A, Liu JJ, Urano T, Sugita M (2005) Net ecosystem carbon dioxide exchange over grazed steppe in central Mongolia. Global Change Biology, 11, 1941-1955.

Lindstrom M, Bates D (1990) Nonlinear mixed effects models for repeated measures data. Biometrics, 46, 673-687.
Liu YY, Evans JP, McCabe MF, de Jeu RAM, van Dijk AIJM, Dolman AJ, Saizen I (2013) Changing climate and overgrazing are decimating Mongolian steppes. PloS one, 8, e57599.

Lyapustin A, Knyazikhin Y (2001) Green's function method for the radiative transfer problem. I. Homogeneous non-Lambertian surface. Applied optics, 40, 3495-3501.

Lyapustin A, Knyazikhin Y (2002) Green's function method in the radiative transfer problem. II. Spatially heterogeneous anisotropic surface. Applied optics, 41, 56005606.

Lyapustin A, Wang Y, Frey R (2008). An automatic cloud mask algorithm based on time series of MODIS measurements. Journal of Geophysical Research, 113, D16207.

Lyapustin A, Martonchik J, Wang Y, Laszlo I, Korkin S (2011a) Multiangle implementation of atmospheric correction (MAIAC): 1. Radiative transfer basis and look-up tables. Journal of Geophysical Research, 116, D03210.

Lyapustin A, Wang Y, Laszlo I, Kahn R, Korkin S, Remer L, Reid JS (2011b). Multiangle implementation of atmospheric correction (MAIAC): 2. Aerosol algorithm. Journal of Geophysical Research, 116, D03211.

Lyapustin A, Wang Y, Laszlo I, Hilker T (2012) Multi-angle implementation of atmospheric correction for MODIS (MAIAC). Part 3: atmospheric correction. Remote Sensing of Environment, 127, 385-393.

Myneni RB, Keeling CD, Tucker CJ, Asrar G, Nemani RR (1997a) Increased plant growth in the northern high latitudes from 1981 to 1991. Nature, 386, 698-702.

Myneni RB, Ramakrishna R, Nemani R, Running SW (1997b) Estimation of global leaf area index and absorbed PAR using radiative transfer models. IEEE Transactions on Geoscience and Remote Sensing, 35 (6), 1380-1393.

National Statistical Office of Mongolia (2012) Available at: http://web.nso.mn:8080/ userdata/Dialog/varval.asp?ma=MAA1\&ti=\&path=../Database/Mongolian/ MAA/\&lang=1 (accessed 4 April 2013).

Opp C, Hilbig W (2003) The impact of overgrazing on natural pastures in Mongolia and Tyva. Berliner Paläobiologische Abhandlungen, 2, 96e98.

Pacyna A (1986) Vegetation of the Sant valley in the Khangai mountains (Mongolia). Fragmenta Floristica Geobotanica, 30, 313-451.

Pinheiro JC, Bates DM (1995) Approximations to the log-likelihood function in the nonlinear mixed-effects model. Journal of Computational and Graphical Statistics, 4, $12-35$.

Pinzon J, Brown ME, Tucker CJ (2005) Satellite time series correction of orbital drift artifacts using empirical mode decomposition. In: Hilbert-Huang Transform: Introduction and Applications, (ed. Huang N), pp. 167-186. World Scientific, New Jersey.

Reading RP, Bedunah DJ, Amgalanbaatar S (2006) Rangelands of Central Asia: Proceedings of the Conference on Transformations, Issues, and Future Challenges, In: USDA Forest Service Proceedings. Fort Collins, CO.

Roujean J-L, Leroy M, Deschamps P-Y (1992) A bidirectional reflectance model of the Earth's surface for the correction of remote sensing data. Journal of Geophysical Research, 97, 20455.

Ross I (1981) The Radiation Regime and Architecture of Plant Stands. Dr. W. Junk, Norwell, MA

Sellers PJ, Tucker CJ, Collatz GJ, Los SO, Justice CO, Dazlich DA, Randall DA (1994) A global $1^{\circ}$ by $1^{\circ}$ NDVI data set for climate studies. Part 2: The generation of global fields of terrestrial biophysical parameters from the NDVI. International Journal of Remote Sensing, 15, 3519-3545.

Steinberg DC, Goetz SJ, Hyer EJ (2006) Validation of MODIS F/sub PAR/products in boreal forests of Alaska. IEEE Transactions on Geoscience and Remote Sensing, 44, 1818-1828.

Sternberg T, Tsolmon R, Middleton N, Thomas D (2011) Tracking desertification on the Mongolian steppe through NDVI and field-survey data. International Journal of Digital Earth, 4, 50-64.

Stumpp M, Wesche K, Retzer V, Miehe G (2005) Impact of grazing livestock and distance from water source on soil fertility in southern Mongolia. Mountain Research and Development, 25, 244-251.

Sugita M, Asanuma J, Tsujimura M, Mariko S, Lu M, Kimura F, .. \& Adyasuren, T. (2007) An overview of the rangelands atmosphere-hydrosphere-biosphere interaction study experiment in northeastern Asia (RAISE). Journal of Hydrology, 333, 3-20.

Tucker CJ (1979) Red and photographic infrared linear combinations for monitoring vegetation. Remote Sensing of Environment, 8, 127-150.

Tucker CJ, Slayback DA, Pinzon JE, Los SO, Myneni RB, Taylor MG (2001) Higher northern latitude normalized difference vegetation index and growing season trends from 1982 to 1999. International Journal of Biometeorology, 45, 184-190.

Tucker CJ, Pinzon JE, Brown ME (2004) Global Inventory Modeling and Mapping Studies, NA94apr15b.n11-VIg. Global Land Cover Facility, University of Maryland, College Park, MD. 
Tucker C, Pinzon J, Brown M et al. (2005) An extended AVHRR 8-km NDVI dataset compatible with MODIS and SPOT vegetation NDVI data. International Journal of Remote Sensing, 26, 4485-4498.

Turner DP, Cohen WB, Kennedy RE, Fassnacht KS, Briggs JM (1999) Relationships between leaf area index and Landsat TM spectral vegetation indices across three temperate zone sites. Remote Sensing of Environment, 70, 52-68.

UNEP (2002) Mongolia: State of the environment. United Nations Environment Programme Pathumthani, Thailand.

Vermote EF, Kotchenova SY, Ray JP (2008) MODIS Surface Reflectance User's Guide v 1.2. Available at: http://modis-sr.ltdri.org (accessed 27 March 2013).

Vetter S (2005) Rangelands at equilibrium and non-equilibrium: recent developments in the debate. Journal of Arid Environments, 62, 321-341.

Wallis de Vries MF, Manibazar N, Dügerlham S (1996) The vegetation of the foreststeppe region of Hustain Nuruu, Mongolia. Vegetatio, 122, 111-127.

Wang D, Morton D, Masek J, Wu A, Nagol J, Xiong X, Wolfe R (2012) Impact of sensor degradation on the MODIS NDVI time series. Remote Sensing of Environment, 119, 55-61.

Wilson AD (1986) Principles of Grazing Management Systems, Proceedings of the International Rangeland Congress. Adelaide, Australia, pp. 221-225.

Yatagai A, Yasunari T (1995) Interannual variations of summer precipitation in the arid/semi-arid regions in China and Mongolia: their regionality and relation to the asian summer monsoon. Journal of the Meteorological Society of Japan, 73, 909-923.

Yiruhan I, Hayashi I, Nakamura T, Shiyomi M (2001) Changes in floristic composition of grasslands according to grazing intensity in inner Mongolia, China. Journal of Japanese Society of Grassland Science, 47, 362-369.
Ykhanbai H, Bulgan E, Beket U, Vernooy R, Graham J (2004) Reversing grassland degradation and improving Herders' livelihoods in the Altai Mountains of Mongolia. Mountain Research and Development, 24, 96-100.

Yong-Zhong S, Yu-Lin L, Jian-Yuan C, Wen-Zhi Z (2005) Influences of continuous grazing and livestock exclusion on soil properties in a degraded sandy grassland, Inner Mongolia, northern China. Catena, 59, 267-278.

Zhao H-L, Zhao X-Y, Zhou R-L, Zhang T-H, Drake S (2005) Desertification processes due to heavy grazing in sandy rangeland, Inner Mongolia. Journal of Arid Environments, 62, 309-319.

Zhu Z, Woodcock CE, Olofsson P (2012) Continuous monitoring of forest disturbance using all available Landsat imagery. Remote Sensing of Environment, 122, 75-91.

\section{Supporting Information}

Additional Supporting Information may be found in the online version of this article:

Appendix S1. Comparison between MAIAC and conventional NDVI. 